\title{
The cognitive neuroscience of creativity
}

\author{
ARNE DIETRICH \\ American University of Beirut, Beirut, Lebanon
}

\begin{abstract}
This article outlines a framework of creativity based on functional neuroanatomy. Recent advances in the field of cognitive neuroscience have identified distinct brain circuits that are involved in specific higher brain functions. To date, these findings have not been applied to research on creativity. It is proposed that there are four basic types of creative insights, each mediated by a distinctive neural circuit. By definition, creative insights occur in consciousness. Given the view that the working memory buffer of the prefrontal cortex holds the content of consciousness, each of the four distinctive neural loops terminates there. When creativity is the result of deliberate control, as opposed to spontaneous generation, the prefrontal cortex also instigates the creative process. Both processing modes, deliberate and spontaneous, can guide neural computation in structures that contribute emotional content and in structures that provide cognitive analysis, yielding the four basic types of creativity. Supportive evidence from psychological, cognitive, and neuroscientific studies is presented and integrated in this article. The new theoretical framework systematizes the interaction between knowledge and creative thinking, and how the nature of this relationship changes as a function of domain and age. Implications for the arts and sciences are briefly discussed.
\end{abstract}

Creativity is a fundamental activity of human information processing (M. A. Boden, 1998). It is generally agreed to include two defining characteristics: "The ability to produce work that is both novel (i.e., original, unexpected) and appropriate (i.e., useful, adaptive concerning task constraints)" (Sternberg \& Lubart, 1999, p. 3). Much has been written about creativity from social, psychological, developmental, cognitive, and historical perspectives, and a number of theories have been proposed from those viewpoints (Amabile, 1983; Csikszentmihalyi, 1996; Eysenck, 1993; Gardner, 1993; Gruber, 1981; Guilford, 1950; Martindale, 1995; Mednick, 1962; Simonton, 1988; Sternberg \& Lubart, 1995; Ward, Smith, \& Finke, 1999; Wertheimer, 1982). However, little is known about the brain mechanisms that underlie creative thinking.

Research on insightful problem solving, creative cognition, and expertise acquisition, as well as historic case studies of individuals with exceptional creative accomplishments have replaced the view that the creative act is a mysterious or even mystical event (Simonton, 2000). Creativity is grounded in ordinary mental processes (M. A. Boden, 1998; Ward et al., 1999; Weisberg, 1993), making creative cognition an integral part of cognitive science and thus neuroscience. Indeed, the view has been expressed that "any theory on creativity must be consistent and integrated with contemporary understanding of brain function" (Pfenninger \& Shubik, 2001, p. 217).

I thank Nelson Cowan, Tony Johnson, Hilde Haider, and Paul Frysh for invaluable help with the manuscript. Correspondence should be addressed to A. Dietrich, Department of Social and Behavioral Sciences, American University of Beirut, P.O. Box 11-0236, Riad El-Solh, Beirut 1107-2020, Lebanon (e-mail: arne.dietrich@aub.edu.lb).
Despite such agreement among investigators, the findings of modern brain research have not been incorporated into research on creativity. Current neuroscientific explanations of creative achievements remain focused on hemispheric asymmetry (e.g., J. E. Boden \& G. M. Boden, 1969; Carlsson, Wendt, \& Risberg, 2000; Katz, 1986; Kinsbourne, 1982; Martindale, 1999). If we are to further our understanding of the generative capacity of the human brain, a broader neuroscientific approach must be taken.

A substantial amount of evidence demonstrates that discrete circuits are involved in specific aspects of higher brain function (for reviews, see Cabeza \& Nyberg, 2000; Damasio, 2001; Duncan \& Owen, 2000). The capacity to identify the brain areas that are recruited during normative information processing, coupled with the data that suggest that creative thinking is the result of ordinary mental processes, forms the foundation for the framework of creativity proposed in this article. A basic assumption of the framework is that neural circuits that process specific information to yield noncreative combinations of that information are the same neural circuits that generate creative or novel combinations of that information.

To integrate the neuroanatomical correlates of mental processes with the knowledge base of the field of creativity, a brief outline of brain function is presented that conceptualizes information processing as hierarchically structured. Such a functional hierarchy localizes the most sophisticated mental abilities, and thus creative mentation, in the zenithal higher order structure: the prefrontal cortex. However, no suggestion is made here that the prefrontal cortex is the "seat of creativity." Rather, the prefrontal cortex contributes highly integrative computations to the conscious experience, which enables novel combinations of 
information to be recognized as such and then appropriately applied to works of art and science.

\section{BRIEF OUTLINE OF FUNCTIONAL NEUROANATOMY}

Modern brain research conceptualizes cognitive function as hierarchically ordered. Evolutionary pressures forced the development of ever more integrative neural structures able to process increasingly complex information. This, in turn, led to increased behavioral flexibility and adaptability. The cerebral cortex, and in particular the prefrontal cortex, is at the top of that hierarchy, representing the neural basis of higher cognitive functions (e.g., Frith \& Dolan, 1996; Fuster, 2002). Historically, consciousness was approached in a similar manner (Markowitsch, 1995), being defined by selection of various attributes, such as self-reflection, attention, memory, perception, and arousal, which were ordered in a functional hierarchy with the frontal lobe necessary for the top attributes. Recent theories of the neural correlates of consciousness similarly emphasize frontal cortex function for higher attributes (e.g., Ashby, Valentin, \& Turken, 2002; Crick \& Koch, 1998; Dehaene \& Naccache, 2001; Dietrich, 2003).

The brain has developed two different types of neural systems, each designed to extract a different kind of information from the environment. On the one hand, the emotional brain is designed to attach a value tag to the incoming information that allows the person to evaluate the biological significance of a given event (LeDoux, 1996). On the other hand, a separate and parallel line of information processing that is devoid of any salient information is designed to perform detailed feature analysis. This perceptual evaluation of the environment is used to construct sophisticated representations that function as the basis for cognitive processing. Each line of information processing contains a functional hierarchy in which increasingly higher order structures perform progressively more sophisticated computations.

These two functional systems can be dissociated in anatomy as well as in the way they process information (e.g., Churchland, 2002; Damasio, 2002; LeDoux, 1996). While anatomical dissociation has received more attention, the process modularity of emotion and cognition - that is, whether or not they compute information in a fundamentally different way-is still a matter of some controversy. However, the case of E.V.R. (Damasio, 1994) suggests that, unlike the computational mode of the cognitive system, emotions are a form of "bio-computation, i.e., dirty, me-relevant computation" (Churchland, 2002, p. 228). E.V.R. had sustained ventromedial prefrontal cortex damage, and cognitive tests showed that he had no deficit in assessing and judging hypothetical scenarios of complex moral and social situations. In addition, he outscored healthy subjects in a variety of standardized tests. Despite his cognitive abilities, a real-life situation did not trigger the execution of appropriate social behaviors. Damasio (1994) suggested that the deficit was confined to "actual" social behavior, because E. V. R failed to assess the emotional (personal) content of the event, which is not necessary for solving a similar but hypothetical scenario. The process modularity of emotions is also evident in artificial intelligence where "failures in programming computers to conform even roughly to common sense, or to understand what is relevant, are an indication of the nonalgorithmic, skill-based nature of rationality" (Churchland, 2002, p. 231).

Initial processing of affective content occurs in various limbic system structures, such as the amygdala (LeDoux, 1996). The computational product of these limbic structures is used by the next higher level of affective processing represented by the cingulate cortex and the ventromedial prefrontal cortex (Damasio, 1994). These structures produce complex emotions and are capable of evaluating the significance of complex social situations. Cognitive processing is represented by another set of limbic system structures, primarily the hippocampal formation, as well as the temporal, parietal, and occipital cortices. The required level of selective attention to process information is also supplied by these structures (J. G. Taylor, 2001). Each track keeps a record of its activity so that emotional memory is part of the emotional circuitry, and perceptual and conceptual memory are part of the cognitive circuitry (LeDoux, 1996).

Although there are multiple connections at various levels between the two information processing systems, full reintegration of emotional and cognitive information does not appear to happen until both types of computations converge back on the dorsolateral prefrontal cortex (e.g., Fuster, 2000b). This region is involved in executive function; that is, it further integrates already highly processed information, formulates plans and strategies for appropriate behavior in a given situation and instructs the adjacent motor cortices to execute its computational product. At all levels of the functional hierarchy, neural structures have direct access to activating the motor system, but behavior that is based on prefrontal activation is most sophisticated.

It is evident from this outline that the prefrontal cortex must be the central structure involved in creative thinking. To understand more thoroughly how the brain might engage in information processing that results in creative thoughts, it is instructive to provide a more detailed review of the functions of the prefrontal cortex and how they relate to concepts of creativity.

\section{PREFRONTAL CORTEX FUNCTION AND CREATIVITY}

Perhaps the single most important functional division in the neocortex is the central fissure. It demarcates the frontal lobe from the three posterior cortices - the temporal, the occipital, and the parietal — which will be collectively referred to as the TOP. The functions of the TOP are different from those of the frontal lobe. The TOP neurons are devoted primarily to perception and 
long-term memory. The primary sensory cortices of all sense modalities are located in the TOP, and its association cortex further assembles and assimilates sensory information decoded initially in the primary cortex. It is generally agreed that the TOP is the site of long-term memory storage (e.g., Gilbert, 2001).

The frontal lobe, located just rostral to the central fissure, does not receive direct sensory input nor store longterm memory. The prefrontal cortex, which comprises approximately half of the frontal lobe in humans, integrates already highly processed information to enable still higher cognitive functions such as a self-construct (Keenan, Wheeler, Gallup, \& Pascual-Leone, 2000; Vogeley, Kurthen, Falkai, \& Maier, 1999), self-reflective consciousness (Courtney, Petit, Haxby, \& Ungerleider, 1998; Vogeley et al., 2001), complex social function (Damasio, 1994), abstract thinking (e.g., Rylander, 1948), cognitive flexibility (Lhermitte, 1983; Lhermitte, Pillon, \& Serdaru, 1986), planning (Norman \& Shallice, 1986; Shallice \& Burgess, 1991), willed action (Frith \& Dolan, 1996), source memory (Janowsky, Shimamura, \& Squire, 1989), and theory of mind (Frith \& Frith, 2001; Povinelli \& Preuss, 1995; Stone, Baron-Cohen, \& Knight, 1998).

Three other cognitive functions of the prefrontal cortex-working memory (Baddeley, 1996; Fuster, 2000a; Goldman-Rakic, 1992), temporal integration (e.g., Fuster, 1995; Knight \& Grabowecky, 1999; Kolb, 1984), and sustained and directed attention (e.g., Posner, 1994; Sarter, Givens, \& Bruno, 2001)—provide the infrastructure to compute these complex cognitive functions by providing a buffer to hold information in mind and order it in space-time (Dehaene \& Naccache, 2001; Duncan \& Owen, 2000). It is this superimposing of already highly complex mental constructs that dramatically increases cognitive flexibility.

The prefrontal cortex is not a single unit. It is functionally divided into ventromedial (VMPFC) and dorsolateral (DLPFC) aspects (e.g., Fuster, 2002; Petrides, 1996). Lesion and functional imaging studies have shown that different prefrontal circuits, along with their respective cortical and subcortical connections, are implicated in specific cognitive abilities. A discernible hemispheric specialization further suggests that these cognitive processes are not global functions of the frontal lobe. For instance, semantic memory retrieval is implemented in the left DLPFC, whereas activation of the right DLPFC is most closely associated with sustained attention (for a review, see Cabeza \& Nyberg, 2000; Duncan \& Owen, 2000). Anatomically speaking, it has been argued that the DLPFC developed from hippocampal tissue and is phylogenetically different from VMPFC tissue (Fuster, 2002; Petrides \& Pandya, 1999). The DLPFC is also heavily interconnected with the TOP regions, whereas the VMPFC is heavily connected to the amygdala and cingulate cortex (Damasio, 1994).

The most common deficit associated with the VMPFC region is impaired social function. This deficit was epit- omized by the famous case of Phineas Gage, who after a freak accident that damaged his frontal lobe, exhibited what is now recognized as the typical frontal syndrome: inappropriate social behaviors, lack of moral judgment, few social inhibitions, few abstract thought processes, an inability to plan for the future, and/or difficulty of maintaining a plan of action. He showed a lack of concern for himself and others and behaved with little regard for social constraints. It appears that the VMPFC region is critical for internalizing the values and societal standards of a person's culture. Damasio (1994) suggested that the VMPFC, with its intricate connections to the limbic system, might assess the personal consequences of one's behavior, and that the resulting emotions are an essential prerequisite to making logical and rational decisions. Given that creativity is both novel and appropriate, it would appear that the ability of the prefrontal cortex to evaluate propriety must be critical to assessing whether a particular new idea is creative as opposed to merely new.

Damage to the DLPFC does not involve changes in personality and emotion. The DLPFC does not receive direct innervation from subcortical structures such as the amygdala that are involved in affective behavior (Petrides \& Pandya, 1999). Its primary input comes from the TOP, and its primary output is the motor cortices. Research has implicated the DLPFC in working memory, directed attention, and temporal integration (Fuster, 2000a; Goldman-Rakic, 1992; Knight \& Grabowecky, 1999; Posner, 1994).

Working memory describes the ability to process information online. It is a monitoring system of ongoing events that temporarily keeps in mind information that is relevant to the situation, so that one can "work" with it. Electrophysiological recordings demonstrate that, as TOP neurons decipher sensory information, a representation of that information is also present in working memory, so it can figure into the immediate decisionmaking process (e.g., Quintana \& Fuster, 1999). Cognitive research has shown that working memory is severely limited in capacity, either in storage, or processing, or both (Baars, 1989; Baddeley, 1996; Cowan, 1995, 2001; Halford, Wilson, \& Phillips, 1998). With its ability to sustain online processing in real time, the working memory buffer appears to be a prerequisite for cognitive flexibility, abstract thinking, strategic planning, access to long-term memory, and sentience. It has been suggested that full-fledged, self-reflective consciousness comes about in these DLPFC circuits (e.g., Baddeley, 2000; Courtney et al., 1998; Cowan, 2001; Dehaene \& Naccache, 2001; Posner, 1994); in other words, our immediate conscious experience of the here and now is made possible by the sustained buffering of information in working memory. It has been suggested that a working memory buffer is critical, indeed a prerequisite, for creative thinking (Damasio, 2001). It allows holding in mind knowledge that is relevant to solving a particular problem. 
The ability to sustain attention is a prerequisite to an effective working memory buffer (Cowan, 2001). Attentional processes in the form of selective perception occur at all levels of the perceptual process, and thus in the TOP. However, intentional control of focus and the maintenance of concentration appear to be a frontal lobe function (e.g., Posner, 1994; Sarter et al., 2001). It has been proposed that the focus of attention is capacity limited, restricting the amount of information that can be held in working memory, as well as central executive processing that can be performed in parallel (Broadbent, 1958; Cowan, 2001; Kane, Bleckley, Conway, \& Engle, 2001). Humans have a great deal of intentional control over what they attend to, and the attentional network of the prefrontal cortex is not only a mechanism to select the content of consciousness (Cowan, 1995; Posner, 1994), but also to maintain the chosen content online long enough for a creative solution to mature. The framework of creativity outlined in this article proposes that there are two types of processing modes, deliberate and spontaneous, that can give rise to creative thoughts. Much evidence exists suggesting that creativity can be the result of defocused attention (see Martindale, 1999), but the ability to deliberately direct attention to pertinent information must be a prerequisite for creative thinking that is the result of effortful, constructive problem solving.

A number of researchers have emphasized the role of the prefrontal cortex in the organization of behavior across time (Fuster, 1995; Knight \& Grabowecky, 1999; Kolb, 1984). Frontal lesions in nonhuman animals have revealed deficits in time estimation and temporal memory (e.g., Dietrich \& Allen, 1998), temporal ordering (Kolb \& Whishaw, 1983), and sequencing (e.g., Kesner $\&$ Holbrook, 1987). In humans, this deficit is most strikingly seen in the inability to plan, formulate strategies, and carry out sequential tasks requiring a step-by-step implementation of behaviors (Jasper, 1995; Milner, 1995; Shallice \& Burgess, 1991). Thus, the prefrontal cortex orchestrates action in accordance with internal goals (E. K. Miller \& Cohen, 2001). It follows that aesthetic or scientific goal-directed behaviors depend on prefrontal activity. It is hard to imagine how creative ideas can occur in one's mind without continuity of thought and without the capacity to order information along the temporal dimension.

Perseveration, or the inability to shift between modes of thinking, is the most reliable deficit associated with damage to the DLPFC (Boone, 1999). Perseveration is perhaps most indicative of a lack of cognitive flexibility and ability to think abstractly. It is commonly tested for and quantified with the Wisconsin Card Sorting Task (WCST), in which cards are sorted by one of three characteristics: color, number, or shape. The patient is required to discover the sorting rule empirically using only feedback from the examiner about selection of the cards. When the examiner changes the sorting rule, patients are required to adapt to the new rule. Patients with DLPFC damage show perseverative errors in this task, continuing to sort according to the old rule even in the face of obvious discrepancy. This is frequently interpreted as a failure of working memory because relevant past behavior is required to perform the task successfully. Functional imaging has shown that the flexible shifting of cognitive sets in normal subjects is accompanied by prefrontal activation (Konishi et al., 1998; Monchi, Petrides, Petre, Worsley, \& Dagher, 2001). A comparable deficit can be produced in rats. A rat in a T-maze is trained over many trials to find food located in one of the T's arms. Once the rule (right or left) is acquired according to some criterion, it is changed to the other arm. After a number of reversals, a strategy emerges that is called win/stay lose/shift, or in other words, the rat acquires the concept of shifting. Prefrontal lesions cause rats to perseverate and adhere to the previously learned rule (e.g., Dietrich, Taylor, \& Passmore, 2001). Given that perseveration to old information is anathema to creative thinking, it is evident that a fully operational prefrontal cortex enables cognition that is necessary for creative ability.

Finally, it appears that the prefrontal cortex exerts inhibitory control over inappropriate or maladaptive emotional and cognitive behaviors. Lhermitte (1983; Lhermitte et al., 1986) documented this tendency by showing that frontal lobe patients are overly dependent on immediate cues. They tend to act on what they see without taking into account the bigger picture. Similarly, such patients show a strong tendency to imitate inappropriate behaviors modeled by others. As Lhermitte put it, "The sight of the movement is perceived in the patient's mind as an order to imitate; the sight of an object implies the order to use it" (Lhermitte et al., 1986, p. 330). Without a fully functional frontal lobe, the patient can utilize only immediate cues and fails to select behaviors based on more universal principles. Thus, the frontal lobe provides for cognitive flexibility and freedom, and releases us from the slavery of direct environmental triggers or the memory stored in the TOP.

Creativity is the epitome of cognitive flexibility. The ability to break conventional or obvious patterns of thinking, adopt new and/or higher order rules, and think conceptually and abstractly is at the heart of any theory of creativity such as Guilford's $(1950,1967)$ concept of divergent thinking. Moreover, the fact that stored knowledge and novel combinations of that knowledge are implemented in two distinct neural structures, the TOP and the prefrontal cortex, respectively, is critical to understanding the relationship between knowledge and creativity, as well as the difference between creative and noncreative thinking.

In conclusion, creativity requires cognitive abilities, such as working memory, sustained attention, cognitive flexibility, and judgment of propriety, that are typically ascribed to the prefrontal cortex. Not surprisingly, the central role the prefrontal cortex must play in creativity has been stressed by other investigators (Ashby, Isen, \& 
Turken, 1999; Ashby et al., 2002; Bekhtereva, Dan'ko, Starchenko, Pakhomov, \& Medvedev, 2001; Bekhtereva et al., 2000; Carlsson et al., 2000; Damasio, 2001; Kornhuber, 1993; Martindale, 1999; Scheibel, 1999).

\section{TYPES OF CREATIVITY}

Production of novelty is not rare in human information processing. One only has to consider the combinational potential presented by human language to appreciate the brain's generative capacity. An assumption of the framework linking creative information processing to normative information processing is that every neural circuit that computes specific information also produces novel combinations of that information. Indeed, novelty might be inevitable in such a chaotic system. Furthermore, it is reasonable to assume that the more integrative the neural structure involved in the computations, the more combinational novelty might occur. On the other hand, the second defining characteristic of creativity, appropriateness, is not inherent in every neural circuit but depends on higher order structures that are capable of assessing a set of very complex and constantly changing rules such as the values implicit in a person's culture. This is compatible with the theory that creativity is essentially a Darwinian process; that is, it entails a variation-selection process (Simonton, 1997, 2003). Ideational combinations are generated all the time, but a selection process is required to determine which ideas are truly creative.

Considering the definition of creativity, it is proposed that there are four basic types of creativity. Novelty production can occur in emotional structures or in cognitive structures, and crossing the type of information with the two modes of processing (deliberate or spontaneous) yields the four basic types. It should be stressed, however, that a given creative act is not suggested to be the manifestation of one of these four types in pure form. Just as any behavioral act is the result of a combination of normative cognition and emotion, the four types of creativity are basic elements of information processing, and creative behavior is ultimately the result of a combination of these basic psychological processes. Once a novel combination has been generated, to turn it into a creative idea, a value assessment by the prefrontal cortex is required. Thus, all four types of creativity share a "final common pathway," regardless of the circuit that generated the novelty.

It is proposed that the role of the prefrontal cortex in the creative process is threefold. First, to evaluate the appropriateness of a novel thought, one has to become conscious of it. Given the view that the working memory buffer of the prefrontal cortex holds the content of consciousness, a novel thought becomes an insight when it is represented in working memory. Information that is not represented in working memory is unconscious to the extent that we cannot reflect or report on it (e.g., Gazzaniga, Ivry, \& Mangun, 1998). Since neural structures at all levels of the functional hierarchy can activate the motor sys- tem, such unconscious novel combinations can produce novel behaviors. However, sophisticated creative behavior is based on the prefrontal integration that follows once unconscious novel thoughts become manifested in consciousness.

Second, insights are only the first step in converting novel combinations of information into creative work. Once an insight occurs, the prefrontal cortex can bring to bear the full arsenal of higher cognitive functions to the problem, including central executive processes such as directing and sustaining attention, retrieving relevant memories, buffering that information and ordering it in space-time, as well as thinking abstractly and considering impact and appropriateness. Innumerous insights turn out to be incorrect, incomplete, or trivial, so judging which insights to pursue and which to discard requires prefrontal cortex integration.

Third, the prefrontal cortex must implement the expression of the insight. The prefrontal cortex orchestrates action in accordance with internal goals (E. K. Miller \& Cohen, 2001), such as aesthetic or scientific goals. In everyday problem solving, planning and executing concurrent subgoals while keeping in mind the main goal are critically dependent on prefrontal activation (Channon \& Crawford, 1999; Koechlin, Basso, Pietrini, Panzer, \& Grafman, 1999). In art as well as science, the expression of a creative insight requires a high level of skill, knowledge, and/or technique that depends upon continuous problem solving. Great works of art or science such as Picasso's Guernica or Einstein's theory of relativity are the result of goal-directed behaviors that took months or years to mature. The creative insight is but the first step in the creative act.

\section{Processing Modes}

The framework of creativity outlined in this article proposes that creative insights can arise in two processing modes-spontaneous and deliberate. Similar distinctions between modes of thinking, for instance, intuition and analysis or explicit and implicit, have been made previously (Ashby et al., 1999; Shirley \& LanganFox, 1996; Simonton, 1975). There is much evidence to support either notion. A number of researchers have pointed out that creative insights are marked by sudden realizations that tend to occur in a mental state that is characterized by defocused attention (Bransford \& Stein, 1984; Eysenck, 1995; Martindale, 1999). Indeed, anecdotal reports in the arts and sciences abound that describe the creative process as automatic and effortless. From Kekulé's daydream of whirling snakes forming a (benzene) ring to Coleridge's poem "Kublai Khan," such flashes of insights are the very cliché of creative genius. It has even been claimed that creativity goes beyond the rational (e.g., Torrance \& Hall, 1980), and the view, originally expressed by Kraepelin, that there is a link between mental illness and creativity, has received much attention (for a review, see Waddell, 1998). In particular, a positive correlation between psychopathology and creativity has been asserted 
for schizophrenia (e.g., Sass, 2000), bipolar disorder (e.g., Jamison, 1993; Rothenberg, 2001), on setting of dementia (e.g., B. L. Miller et al., 1998), and depression (e.g., Post, 1994). In addition, drugs such as alcohol and opium that lower inhibition and attentional focus, have a longstanding reputation of fostering creative inspiration in the arts (Goodwin, 1992; Post, 1996).

Other researchers have argued the opposite viewthat is, creativity is the result of deliberate and methodical problem solving (e.g., M. A. Boden, 1998; Guilford, 1982; Sternberg \& Lubart, 1999; Weisberg, 1993). From Watson and Crick's discovery of DNA to Edison's inventions and Bach's Brandenburg Concertos, it is abundantly clear that creative work can also be the result of laborious trial and error.

To integrate these seemingly conflicting positions, it has been suggested that creative insights can occur in both processing modes (Finke, 1996). Given the astronomical amount of sensory information, attention is believed to be "the result of a limited information processing capacity" (Broadbent, 1958, p. 68). In a recent review of the available literature, Cowan (2001) argued that this limited capacity caps the amount of information that can be held concurrently in the focus of attention, and thus working memory, to four independent chunks or items. In addition to this limited capacity, research in cognitive psychology has shown that focused attention is a taxing mechanism and cannot be maintained indefinitely (e.g., Posner, 1994). As a consequence, mental states that are marked by defocused attention or drifting, such as daydreaming, might simply be the inevitable result of the constant demands placed on the attentional system to selectively process information (Singer, 1978). Contrary to the conscious brain, the unconscious brain appears to be a parallel processor (e.g., Gazzaniga et al., 1998), so that novel combinations of information are constantly generated, regardless of the state of attentional control. Given that the working memory buffer of the prefrontal cortex holds the content of consciousness, and that the attentional network of the prefrontal cortex is the mechanism to select and limit the content, it is hypothesized in the present article that the main difference between deliberate and spontaneous modes of processing is the method used to represent the unconscious novel information in working memory. While deliberate searches for insights are instigated by circuits in the prefrontal cortex and thus tend to be structured, rational, and conforming to internalized values and belief systems, spontaneous insights occur when the attentional system does not actively select the content of consciousness, allowing unconscious thoughts that are comparatively more random, unfiltered, and bizarre to be represented in working memory.

Several lines of evidence corroborate the notion that deliberate insights are qualitatively different from spontaneous insights. Data strongly support the hypothesis that the prefrontal cortex, and in particular the DLPFC, is recruited in long-term memory retrieval (for reviews, see
Cabeza \& Nyberg, 2000; Hasegawa, Hayashi, \& Miyashita, 1999). Neuroimaging studies have implicated the prefrontal cortex in semantic retrieval (e.g., Bruckner, 1996; Cadoret, Pike, \& Petrides, 2001), episodic retrieval (e.g., Desgranges, Baron, \& Eustache, 1997; Nyberg, 1998), autobiographical retrieval (Fink et al., 1996), solving "tip of the tongue" phenomena (e.g., Kikyo, Ohki, \& Sekihara, 2001), priming (Janowsky et al., 1989), and explicit categorization (Ashby et al., 1999).

From these data, it can be concluded that the prefrontal cortex has a search engine that can "pull" taskrelevant information from long-term storage in the TOP areas and temporarily represent it in the working memory buffer. Once online, the prefrontal cortex can use its capacity for cognitive flexibility to superimpose the retrieved information to form new combinations. Recently reported empirical evidence substantiates the notion that creative behavior can be mediated by a memory searchbased mechanism (Friedman \& Förster, 2002). There is good reason to assume that either process is inherently structured - that is, the search engine, as well as the recombination of stored items, operates under a number of constraints. Given the evidence that the prefrontal cortex houses a person's cultural values and belief system (Damasio, 1994), the search engine is likely to be predisposed to retrieve knowledge that is consistent with his or her world view and past experiences.

There is abundant evidence suggesting that perception and cognition are strongly dependent upon a preconceived mental structure (see Gazzaniga et al., 1998). In addition, evidence from creativity research indicates that past knowledge or conscious thinking about a problem can be detrimental to solving it (DeBono, 1968; Frensch \& Sternberg, 1989; Guilford, 1950; Koestler, 1964; Lunchins \& Lunchins, 1959; Schooler \& Melcher, 1995), suggesting that solutions that would violate what is known about the world are not readily considered in effortful creativity. It is further postulated that database searches and cognitive flexibility operate using formal logic (e.g., A causes B), holding assumptions about meaningfulness, and preempting, for efficiency reasons, "remote associations" (Mednick, 1962, p. 220) or counterintuitive paths. Thus, while the deliberate mode allows the thinker to direct cerebral capacities to a particular problem, it has the disadvantage of limiting the solution space.

This type of creativity might be considered analogous to M. A. Boden's (1998) notion that creative thinking is the "exploration of a structured conceptual space." As she writes, "Many human beings - including (for example) most professional scientists, artists, and jazz-musicians - make a justly respected living out of exploratory activity. That is, they inherit an accepted style of thinking from their culture, and then search it, and perhaps superficially tweak it, to explore its contents, boundaries, and potential" (p. 348). Furthermore, according to Scheibel (1999), "we must assume that the more nimble the prefrontal cortex, the more capable it is of playing with new 
combinations of stored items" (p. 3). Empirical evidence for prefrontal activation during effortful problem solving has been reported (see Ashby et al., 2002, for a review; Bekhtereva et al., 2001; Bekhtereva et al., 2000; Carlsson et al., 2000).

In addition to the limited solution space, any information that is retrieved deliberately and is thus explicitly available for conscious manipulation is subject to the capacity limit of working memory (Cowan, 2001). Carefully controlled experiments in which subjects are prevented from rehearsing or chunking support a capacity limit of $4 \pm 1$ items that can be held in working memory at a time (Cowan, 2001). The more famous $7 \pm 2$ is a compound estimate of the capacity limit that allows for executive processes such as rehearsing and chunking but is thought to be more typical of real-world situations. Either way, working memory limits are a critical consideration for deliberate creativity because they constrain the number of possible ideational combinations.

This capacity limit of four chunks appears to be valid only if the chunks are part of a coherent scene. If two chunks are logically inconsistent or mutually exclusive to common sense, such as the Necker cube, the capacity limit is even more narrow (Baars, 1989; Cowan, 2001). In those circumstances, humans appear to be able to process only a single item. This restricts even further the creative potential of the deliberate processing mode and is nicely illustrated by the amount of time it typically takes to combine two seemingly conflicting ideas into a single concept - for instance, the fact that electromagnetic radiation is a wavicle: a wave and a particle.

Alternatively, it has been suggested that "working memory limitations are best defined in terms of complexity of relations that can be processed in parallel" (Halford et al., 1998, p. 723). Halford et al. have argued that the number of dimensions humans can manipulate concurrently is one quaternary relation. Information of greater complexity overloads the capacity limit and invokes executive processes that collapse dimensions into fewer chunks and/or process chunks in a serial manner. This course of action, however, makes some information temporarily inaccessible. Regardless of whether the capacity limit is understood as a storage limit of four items, or a complexity limit of one quaternary relation, it is clear that the ability to form novel associations deliberately is severely restricted by the bottleneck of consciousness.

In contrast to the deliberate processing mode, creativity due to spontaneous insights is presumed to be qualitatively different because it is not initiated by prefrontal database searches that are limited to preconceived mental paradigms, as well as quantitatively because information is not subject to the capacity limit. During the inevitable times when the attentional system is downregulated, thoughts that are unguided by societal norms and unfiltered by conventional rationality become represented in working memory (Dietrich, 2003). In such a mental state, conscious thinking is characterized by unsystematic drifting, and the sequence of thoughts mani- festing itself in consciousness is more chaotic, permitting more "loosely connected" associations to emerge. This is consistent with the view that creativity is a stochastic combinational process (Simonton, 2003) - that is, creative behavior entails an element of chance. Recent research has also shown that the DLPFC is activated by surprise violations of learned associations (Fletcher et al., 2001), suggesting that novel combinations of information that contradict conventional wisdom might have a lower threshold to enter conscious awareness.

Conscious thoughts that are unguided by prefrontal activity are by no means random. Although a number of theories describe the nature of the brain's representation of knowledge, there is a consensus that long-term memory is stored in associative networks (e.g., Anderson \& Bower, 1973; Collins \& Loftus, 1975; for a recent review, see Gabrieli, 1998). Similarly, hippocampal-dependent memory is thought to be associative. Hence, memory recall follows rules that predict the likelihood of retrieval of a given stored item. Research on priming, implicit memory, and insightful problem solving support this assumption (e.g., Ashby et al., 1999; Nisbett \& Ross, 1980; Weisberg \& Alba, 1981). In addition, it was noted early (Hebb, 1939) that people with frontal lobe lesions perform normally on conventional intelligence tests, suggesting that knowledge can be acquired and manipulated without prefrontal integration. It follows that, even without the guidance of the integrative prefrontal cortex, spontaneous insights are unlikely to be irrational. Indeed, empirical evidence demonstrates that many "insights occur without much warning, in a manner similar to perceptual restructuring" (Baker-Sennett \& Ceci, 1996; Metcalfe, 1986; Ward et al., 1999, p. 195), suggesting that the spreading activation through a knowledge-based network alone can yield a new, sophisticated Gestalt. Thus, new ideas can be assembled unconsciously and then represented in working memory in their finished form.

Moreover, it is argued in the present article that the spontaneous processing mode is the underlying mechanism for intuition, a concept closely related to insight and creativity. A large body of evidence from neuroscientific and psychological studies suggests that we are aware of the product of neural computations but not what produces it (see Gazzaniga et al., 1998). Consequently, neither processing mode, deliberate or spontaneous, offers a window into the mechanism of how knowledge is computed. However, if intuition is "the ability to arrive at a solution without reasoning" (Shirley \& Langan-Fox, 1996, p. 564), intuition can be conceptualized as knowledge obtained while the frontal attentional system does not control the content of consciousness, which would result in a mental state in which knowing occurs without intentional reasoning.

Additional evidence that prefrontal activation provides the basis for the qualitative difference between the two modes of processing comes from altered states of consciousness. REM sleep is a mental state that is marked by prefrontal inactivity (Braun et al., 1997) and is charac- 
terized by mentation that is largely void of prefrontaldependent cognition (Hobson, Pace-Schott, \& Stickhold, 2000). For instance, self-reflection is absent (Rechtschaffen, 1978), time is distorted with past, present, and future freely exchanged (Hobson, 1988), and volitional control is greatly diminished (Hartman, 1966). There is also little indication of abstract thinking, active decision making, cognitive flexibility, and focused attention in dream stories. The capacity for semantic and episodic retrieval of specific memories, which relies heavily on DLPFC areas (Cabeza \& Nyberg, 2000), is also greatly compromised.

According to Hobson and McCarley's (1977) activation-synthesis model, the brainstem's activation of memory during REM sleep is random, and dream stories are the result of the brain's attempt to make sense out of the activation without the help of the integrative capacities of the prefrontal cortex. Furthermore, the bizarreness of a dream is related to the extent of the prefrontal hypofunction (Hobson et al., 2000). Not surprisingly, dreams rarely conform to societal values and conventional wisdom. Yet, more often than not, a coherent story line emerges, presumably due to the associative nature of subsequent activation. Dreaming is regarded by many as the mental state with the most creative potential (e.g., Hobson, 1988), because the pattern of cortical activation allows for unregulated and unlimited combinational creativity due to the coactivation of stored items that are not closely associated by conventional wisdom. Thus, dreaming might be regarded as the most extreme form of the spontaneous processing mode and can give rise to insights that are difficult to come by during normal waking consciousness.
It has been argued that daydreaming is also an altered state of consciousness attributable to prefrontal cortex downregulation, albeit not as profound as dreaming (Dietrich, 2003). Anecdotal and historical accounts highlight the fact that associative combinational creativity during altered states such as dreaming or daydreaming can play a vital part in the creative process for the arts and the sciences.

\section{Description of Basic Types}

The content of consciousness can thus be determined by deliberate and/or spontaneous modes of processing, each of which can direct computations in cognitive and/ or emotional structures. Figure 1 provides a schematic representation of the resulting four possible types of creative insights. Again, it should be explicitly clear that no suggestion is made here that creative insights are exclusively of one particular type. Rather, these four types should be conceptualized as the extremes of two dimensions, deliberate/spontaneous and cognitive/emotional. Consequently, creative works arise naturally from a mix of these four basic components. For instance, an emotionally inspired painting requires the employment of perceptual/cognitive processes such as spatial reasoning, while any scientific endeavor entails emotions such as surprise, evaluation of importance, or motivation.

Deliberate mode-cognitive structures. Neuroanatomically speaking, insights of this type are instigated by the prefrontal cortex. The frontal attentional network is recruited to search for task-relevant information in the TOP. The subsequent activation of TOP areas is brought online, so that prefrontal circuits that enable various other higher cognitive functions can manipulate the informa-

\section{Knowledge Domain}

Emotional Cognitive

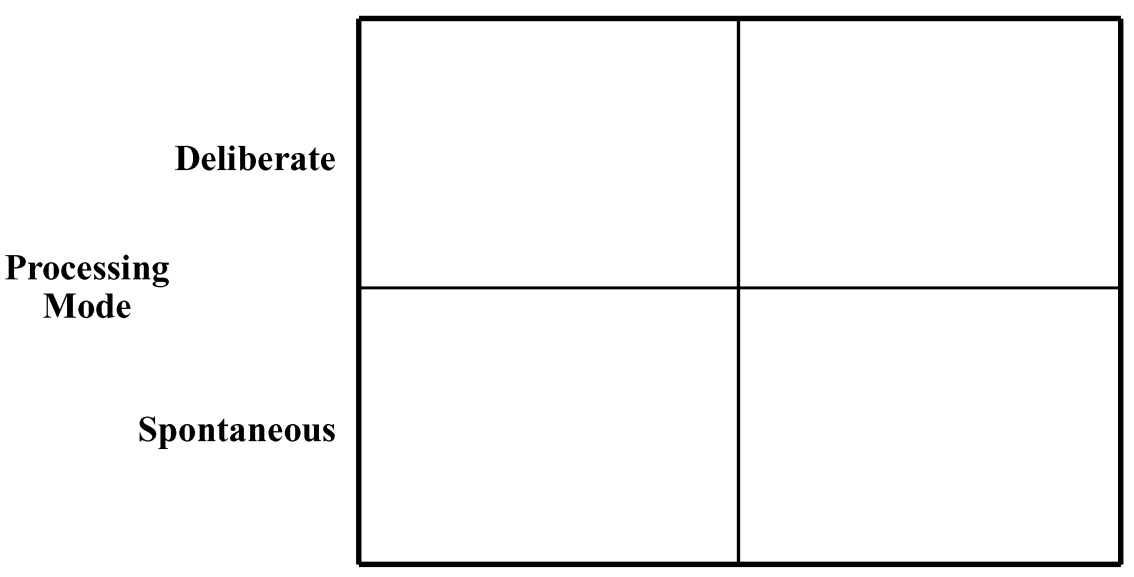

Figure 1. It is proposed that there are four basic types of creative insights, each mediated by a distinctive neural circuit. Creative insights can be the result of two processing modes, deliberate and spontaneous, each of which can guide neural computation in structures that contribute emotional content and in structures that provide cognitive analysis. Crossing the two processing modes with the type of information yields the four basic types of creativity. 
tion. Considering the evidence implicating the hippocampus in the consolidation of declarative memory (Squire, 1992), it must be assumed that for the retrieval of recent memory the hippocampal formation is recruited, as well. Prototypical examples of deliberate/cognitive creativity are the methodical piecing together of the structure of DNA and Edison's systematic approach to inventing.

It is suggested in the present article that the quality of these types of insights is closely related to two factors. First, a prerequisite for creativity in a cognitive domain must be the number of domain-specific items stored in TOP areas. The more knowledge is readily available, the more relevant items can be "juggled" in working memory. The quality of this type of insight depends directly on expertise, which is evidenced by the fact that few inventions or scientific breakthroughs were ever made by individuals with an "uneducated" TOP. Considering that the definition of creativity includes some form of appropriateness, this type of creativity appears to be domain specific. Second, since it is well known that expertise alone does not constitute creativity (Weisberg, 1999), quality must also depend on how "nimble" (Scheibel, 1999, p. 3) the prefrontal cortex is. This factor would appear to constitute a general or domain-independent trait for creativity.

Deliberate mode-emotional structures. Again, this type of insight is instigated by the frontal attentional network. However, instead of searching TOP areas for relevant information, attentional resources are directed toward retrieving affective memory that is stored in emotional structures. A prototypical example of this type of creativity is an insight gained during psychotherapy. The resulting item is temporarily represented in the working memory buffer and can thus be consciously manipulated for further insights. Considering the evidence that basic emotions are processed by limbic system structures such as the amygdala and more complex social emotions by the cingulate cortex and the VMPFC (Damasio, 1994; LeDoux, 1996), it is likely that insights of this type depend heavily on the specific emotion. As reviewed earlier, limbic system structures such as the amygdala do not have direct connections to the dorsolateral prefrontal cortex (Petrides \& Pandya, 1999). In addition, although the amygdala has a massive projection to the VMPFC, it receives few afferent fibers from the VMPFC in return (LeDoux, 1996). Consequently, the limited ability of the prefrontal cortex to direct neural processing in the amygdala (LeDoux, 1996) makes it doubtful that insights based on basic emotions can be deliberate. There is no neuroanatomical limitation for deliberate insights that are based on complex social emotions because the DLPFC is richly interconnected with the VMPFC and the cingulate cortex. Nevertheless, emotional insights that arise due to prefrontal involvement are likely to conform to a person's norms and values. It would appear that this type of insight is independent of domain-specific knowledge, since emotional experiences are universal.
Thus, deliberate emotional insights are principally enabled by an "endowed" prefrontal cortex.

Spontaneous mode-cognitive structures. Neuroanatomically speaking, this type of insight has its origin in TOP areas during associative unconscious thinking. The involvement of the basal ganglia in implicit learning and execution of automatic behaviors (see Ashby et al., 1999; Mishkin, Malamut, \& Bachevalier, 1984) suggests that the basal ganglia also takes part in information processing in the spontaneous mode. Due to the periodic downregulation of the frontal attentional system, such thinking is allowed to enter consciousness when it is spontaneously represented in working memory. Data showing that DLPFC activation during surprise violation of learned associations (Fletcher et al., 2001) suggest further that novel combinations that do not conform to convention might have a lower threshold for being represented in working memory. Because there is no apparent effort or intention associated with these intuitive insights, they are often described as mysterious and indicated by such metaphors as "being hit by a ton of bricks," or the proverbial light bulb turning on.

Problem solving is marked by impasses, particularly when the solution requires "outside the box" thinking. It has been shown that impasses are broken by the relaxation of constraints (Knoblich, Ohlsson, Haider, \& Rhenius, 1999). One common method to overcome impasses is known as incubation, which "refers to the process of removing a problem from conscious awareness temporarily as a means of gaining new perspectives on how to solve it" (Finke, 1996, p. 389). It is plausible that incubation is successful because it leads to the spontaneous processing mode, which in turn results in the relaxation of constraints. Evidently, the experience of trying for hours to desperately solve a problem only to have the solution "pop up" into consciousness, while performing an unrelated, mundane task, is a commonly reported phenomenon.

Some of the most brilliant ideas in the history of science are of this type. For instance, Newton is said to have thought of gravity while watching a falling apple; Kekulé was daydreaming in his study in Ghent when the idea of the benzene structure hit him; Einstein thought of relativity while imagining himself riding on a beam of light; and Poincaré was stepping on a bus when he realized that Fuchsian functions are identical to transformations of non-Euclidian geometry (e.g., Weisberg, 1993). The quality of these types of insights depends on expertise. If relevant information is not committed to memory, it cannot be superimposed in working memory during times of defocused attention. Or as Louis Pasteur said, "In the world of observation, chance only favors the prepared mind."

Spontaneous mode-emotional structures. This type of insight occurs when the neural activity of structures that process emotional information is spontaneously represented in working memory. Because conscious information processing is severely limited in time and capacity, neural structures are thought to compete for access to 
consciousness (Pinker, 1999). Since emotions signify biologically significant events, neural activation in emotional structures make for "loud" signals that are designed to enter consciousness and impress the organism. Not surprisingly, intense emotional experiences create a strong need for creative expression (Torrance, 1988). Prototypical examples of spontaneous/emotional creativity include artistic expression such as Picasso's Guernica or Coleridge's poem "Kublai Khan."

The experience of spontaneously generated emotional information entering consciousness is likely to have a profound effect that engenders a distinct phenomenological state. It is perhaps the mechanism that results in what is referred to as a revelation, an epiphany, or a religious experience. While the emotional nature of the insight certifies to its importance, the unintentional nature of the insight adds to the conviction that such experiences must contain universal truth.

Again, because emotions do not require specific knowledge, insights based on emotional processing are not domain specific. However, creative work based on these insights might require specific skills for appropriate expression.

\section{RECONCEPTUALIZING CONTROVERSIES IN CREATIVITY RESEARCH}

By differentiating among types of creativity, the theoretical framework proposed in this article can help disentangle some of the classical controversies regarding the nature of creativity. Two fundamental issues, the relationship between creativity and knowledge, and the effects of age on creativity, are addressed.

\section{Creativity and Knowledge}

It has been widely accepted in the literature that knowledge is essential for creative thinking. However, there is less agreement on the nature of this relationship. On the one hand, it is thought that a positive correlation best describes the relationship between knowledge and creativity (Gruber, 1981; Hayes, 1989; Weisberg, 1993, 1999). Indeed, the view has been expressed that "all problem solving is based on knowledge" (Weisberg, 1993, p. 117). On the other hand, since "creative thinking by definition goes beyond knowledge" (Weisberg, 1999, p. 226), some researchers assert that too much knowledge may restrain creativity. Bearing in mind the evidence for negative transfer of past experiences to new problem solving tasks (DeBono, 1968; Frensch \& Sternberg, 1989; Guilford, 1950; Koestler, 1964; Lunchins \& Lunchins, 1959; Schooler \& Melcher, 1995), proponents of this view postulate that the relationship between knowledge and creativity is best described by an inverted$\mathrm{U}$ function.

By distinguishing among subtypes of creative thinking, it becomes feasible to study this relationship in a more systematic manner. First, it is imperative to recognize that knowledge and creativity recruit different brain circuits. While knowledge is primarily stored in TOP areas, creativity is enabled by the cognitive capabilities provided primarily by the DLPFC. With respect to the evidence for discrete circuits in specific brain functions (e.g., Cabeza \& Nyberg, 2000), it has been noted that "subtle modifications in the function of such circuits are likely to account for the different cognitive capabilities and talents observed in the normal human population" (Pfenninger \& Shubik, 2001, p. 216). For instance, it has been shown that individual differences in attentional control are related to working memory capacities (Conway, Cowan, \& Bunting, 2001) and that these variables affect task performance (Kane et al., 2001) and by extension, creative problem solving.

Accordingly, one could imagine an individual who possesses an "endowed" TOP but a less-remarkable prefrontal cortex. Such an individual would have encyclopedic knowledge of a particular discipline but would make only minor contributions to its advancement. This possibility could account for the observation that knowledge does not constitute creativity. On the other hand, one could imagine an individual of the opposite predisposition-that is, possessing an endowed prefrontal cortex but a normative TOP. As mentioned above, if relevant information is not stored in memory, it cannot be brought online by TOP circuits and is thus unavailable for prefrontal modules to be included in the computation of creative solutions. It follows that such an individual might be a rich source of new ideas but would be unlikely to augment existing knowledge in a meaningful way. Either case, if correct, would argue against the notion that knowledge and creativity are positively correlated in a simple manner. Rather, optimal levels of creative output in a knowledge-based domain would require exceptionally capable circuits in both the TOP and the prefrontal cortex. Given the evidence that performance on conventional intelligence tests is frequently unaltered by mild prefrontal damage (Hebb, 1939), a similar argument could be made for the relationship between intelligence and creativity.

By proposing that creative insights based on emotional computations are universal, and thus independent of formal knowledge, the relationship between knowledge and creativity can be refined even further. In particular, the role of knowledge in creativity is proposed to be domain specific - that is, the greater the knowledge base of a domain, the more formal knowledge is required for truly innovative work within it.

It might be useful at this point to reiterate the distinction between creative insights, which are conscious realizations that occur in working memory, and creative expression, which is the implementation of that insight. For the arts, it is argued that creative insights do not require specialized knowledge; however, their expression does require exceptional skill. For instance, Guernica was inspired when Picasso witnessed the Condor Legion brutally destroying the town of Guernica in the Spanish Civil War. Picasso's work is not based on any historic, military, or other knowledge that can be acquired by formal education. It is based on understanding human suffering, in- 
justice, and fear. It is likely that other witnesses to the event had similar experiences of empathy, but Picasso had a special way of expressing it. Similar arguments can be made for other creative arts. Modern popular music requires little formal knowledge, often as little as a few simple chords, but few people would argue that the Beatles were not creative. Equally, creativity in literature and poetry is not based on special knowledge of grammar or a degree in comparative literature. Once the specific mechanics of expression are mastered, creativity in the various arts is based on emotional reactions to environmental stimuli. This does not preclude the possibility that the creative artist possesses a finely honed emotional brain. For the sciences on the other hand, creative insights, as well as their creative expression in the form of designing and implementing experiments, depend heavily on formal knowledge.

Hayes (1989) and Gardner (1993) have proposed what is known as the 10-year rule, which holds that a period of deep immersion, regardless of discipline, precedes creative master-level work. It is suggested here that this period of incubation is devoted more to the fine-tuning of expression in the arts, whereas it is devoted more to the acquisition of formal knowledge in the sciences. Perhaps this is best thought of as a continuum rather than a rigid dichotomy with the arts relying more on emotional knowledge and the sciences relying more on cognition. This notion might also shed some light on the fact that original creative achievements in the arts can be appreciated by a wide audience, which is not the case for the sciences.

\section{Age and Creativity}

The division of creative thinking into four distinct types also bears significantly on one of the oldest research topics in the field - that is, how creativity changes as a function of age (e.g., Lehman, 1953; Simonton, 1999). If the prefrontal cortex is, as proposed in this framework, the pivotal neural structure mediating creative behavior, creativity ought to be closely related to prefrontal cortex development across the life span.

The prefrontal cortex is the last structure to develop phylogenically and ontogenically (Fuster, 2000b). In humans, it does not fully mature until the early $20 \mathrm{~s}$. This conforms to frequent claims and might well be the underlying reason why the creativity of children is less structured and appropriate. In terms of the present framework, children's creativity can perhaps be conceptualized as somewhat limited to the spontaneous processing mode, with the added disadvantage of limited amounts of knowledge stored in TOP. Likewise, empirical evidence suggests that prefrontal functions are among the first to deteriorate in old age. For instance, performance in the WCST is stable in mid-life and then declines as a function of age in a linear fashion, particularly the ability to adapt to changing rules (Axelrod, Jiron, \& Henry, 1993). In repeated reversal paradigms that test for cognitive flexibility and working memory, aging rats show comparable perseveration to old information (Means \& Holstein, 1992). These results suggest that the elderly are less able to inhibit well-learned rules and have less independence from immediate environmental cues or memories stored in the TOP. Consequently, one would expect creative achievement to peak in mid-life at the height of prefrontal capacity.

Historiometric studies are consistent with this pattern. In a recent review, Simonton (1999) stated, "we can now conclude with great confidence that . . creative output tends to be a curvilinear, inverted backward-J function of age" (p. 122). He further concluded that the zenith of this function varies by domain. Although the average occurs between the ages of 35 and 39, mathematicians and musicians reach their prime earlier, while historians and philosophers peak later (Simonton, 1997).

Simonton (1997) has convincingly demonstrated that "creative productivity is a function of career age, not chronological age" (p. 70). Although career age and chronological age are highly correlated, latecomers to a discipline show the same career trajectories and landmarks, as well as conformity to the 10-year rule (Simonton, 1997, 2003). For instance, mathematicians peak on average at 26.5 years of career age, while historians peak at 38.5 (Simonton, 1997). Because prefrontal-dependent mental functions do not significantly decline until old age, the distinction between chronological and career age can be accommodated as long as the creator's career onset is not at an advanced chronological age. In such a case, the career trajectory might be altered in one or more important ways due to the premature (in terms of career age) decline in prefrontal functions, even if the creator lives until very old age.

It is remarkable that revolutionary advances in science, as opposed to paradigmatic or normal science (Kuhn, 1970), particularly in theoretical physics, are predominantly made by individuals in their 20 s or individuals very near career onset. A long list of eminent physicists including Bohr, Chadwick, Einstein, Fermi, Feynman, Gell-Mann, Heisenberg, Pauli, and Rutherford seem to exemplify this most strikingly. This curiosity is known as the Planck hypothesis, which states that younger scientists are more receptive to innovation (e.g., Hull, Tessner, $\&$ Diamond, 1978). Even more curious is the observation that scientists who made major, revolutionary contributions early in their careers rarely made a second one of equal impact at an advanced career age, suggesting that age rather than individual differences is the responsible variable. In music, on the other hand, creative achievement peaks early and can be sustained until old age.

It has been proposed that creativity is stochastic in nature and that creativity in the arts and sciences "differ in the extent to which that stochastic process is constrained" (Simonton, 2003, p. 484). In either discipline, the start of creativity coincides with the maturation of the prefrontal cortex. However, a major difference between music and physics is that the latter requires constant adaptation to a new set of rules. Physics is a field with a rapidly growing knowledge base, which means that previously successful responses have to be modified to fit new paradigms. Again, a striking parallel can be drawn to performance 
on the WCST, in which the elderly have little trouble adapting to the first sorting rule but seem unable to inhibit knowledge of this rule when it changes. They also report awareness that the old rule no longer applies, but they continue to emit habitual behavior nonetheless. Consequently, the decline of cognitive flexibility due to aging might affect scientists more readily than artists, who can continue to operate creatively on the first set of rules they acquired.

This tendency to adhere to outdated rules might be compounded by the fact that mental states that enable the spontaneous processing mode, such as daydreaming, go dramatically down with age (Singer, 1975). Thus, in addition to perseveration, the deliberate processing mode, which favors solutions that tend to be consistent with a person's belief system, becomes the more dominant problem solving mode of thought. This is consistent with the previously cited data showing that negative transfer and past experience can interfere with creativity. It is also consistent with the observation that revolutionary science, as opposed to paradigmatic science, is rarely performed by scientists of an advanced career age. It seems that, as we age, a certain version of reality becomes so "hardwired" through decades of reinforcement that the continuously diminishing ability for cognitive flexibility is overpowered. Or in Nietzsche's words, "convictions are greater enemies of the truth than lies."

The present framework is also able to account for the historiometric observation that historians and philosophers achieve their zenith later in life. Unlike the sciences, history is not a reductionistic field in which the knowledge base can be compacted into a manageable set of equations and concepts. In terms of Simonton's (1997, 2003) stochastic model of creative output, physics and history differ in their ideation rates (i.e., the rate at which new combinations are emerging) and elaboration rates (i.e., the time it takes to convert insights into creative products). Thus, it is suggested that in history, although the prefrontal cortex reaches maximal potential at the same time as in physics, additional time is needed to understand complex, multifactorial subjects and commit them to memory. There is a view among historians that eminence in the field does not occur before the age of 40, and indeed, there are no 25-year-old savant historians. Also, few philosophers and historians submitted more than one original idea to the edifice of knowledge, demonstrating that the cognitive inflexibility that seems to accompany aging operates in all knowledge-based domains.

\section{DIRECTIONS IN FUTURE RESEARCH}

Direct empirical evidence for the brain mechanisms underlying creative thinking is remarkably scarce. The present framework is largely based on the cognitive neuroscience of normative information processing, coupled with the putative notion that creativity is grounded in ordinary mental processes and is therefore eminently testable with the tools of modern neuroscience and cog- nitive psychology. A few possible lines of research are outlined.

The proposed framework offers a point of attack for future research that should be primarily aimed at establishing a more direct link between creativity and neuroscience. Most of the empirically derived knowledge base in creativity is built on psychometric measures of creativity. Despite the recent proliferation of hundreds of creativity tests, very few tests such as Guilford's (1967) test of divergent thinking, Torrance's (1974) test, Duncker's (1945) candle problem, or the Remote Associates Test (Mednick, 1962) are widely accepted in the literature. Together, these tests provide timed measures of fluency, flexibility, originality, and elaboration, and are generally identified as either problem solving tasks (deliberate) or open-ended tasks (spontaneous). In addition, some tests are generally regarded as cognitive in nature, while others take into account personality variables such as emotionality.

Due to the lack of communication between neuroscience and creativity research, none of these psychometric measures has been used in combination with functional neuroimaging tools, optical imaging tools, transcranial magnetic stimulation, or EEG equipment. First, the present framework makes clear and specific predictions about the activation of specific brain regions during creative thinking. For example, creativity tests such as the candle problem or the Remote Associates Test (RAT) are classified as involving deliberate and innovative problem solving and have only a very limited number of correct answers. The framework predicts these tests to be associated primarily with the activation of the DLPFC regions but not the VMPFC or TOP regions. On the other hand, various subtests of the Torrance test are open ended and thus require the spontaneous generation of as many items as possible (e.g., name all things that are red or all things that one can do with a safety pin). It is predicted that such tests require the spreading activation through a knowledge-based network and thus primarily the activation of the TOP regions more than the DLPFC regions.

Second, this line of reasoning can be extended to conditions that are characterized by altered prefrontal function, such as neurological disorders, psychological disorders, or altered states of consciousness. For instance, patients with prefrontal damage are predicted to be more impaired in deliberate problem solving than in spontaneous-type creativity tests. Similarly, schizophrenics show hypofrontality (S. F. Taylor, 1996) and should score poorly on the RAT or the candle problem, while having little trouble generating original ideas of what to do with a safety pin. Depression might be particularly interesting because research shows that it is associated with hyperactivity in the VMPFC region but hypoactivity in the DLPFC region (see Mayberg, 1997). The present framework not only predicts that creative ability is altered in those individuals but can make precise predictions in what direction, and for what type of creativity. If this is the case, the 
link between mental illness and creativity can be described more precisely, as this connection is only reported for artists, writers, and musicians, but not scientists. Finally, the framework generates similar predictions for altered states of consciousness (drug-induced states, hypnosis, or distance running) that temporarily decrease prefrontal activity (Dietrich, 2004). The induction of these mental states can be used to conduct empirical tests of the framework.

A third possible line of research might make use of the fact that emotion influences cognitive processes. For instance, positive affect improves performance on a variety of cognitive tests (Ashby et al., 1999). This work typically involves exposure to a short film clip that evokes either a positive, neutral, or negative mood. The framework predicts that these emotional manipulations would influence certain types of creativity more readily than others.

Finally, and perhaps most important, the framework can be used to develop new and more precise psychometric measures of creativity. The generally poor validity and inconsistent results of existing tests is recognized as one of the biggest hurdles to progress in creativity research. The framework suggests that future tests would benefit from the intentional incorporation of cognitive processes that are associated with specific brain areas. For instance, working memory, sustained attention, or semantic memory retrieval require prefrontal activation and elements in creativity tests requiring their use can provide insight as to the dependence of creativity on these psychological processes or specific brain regions.

Equally important may be the use of psychological processes that have not been used at all as elements in creativity tests. For instance, the ability to use a theory of mind (ToM) depends on the prefrontal cortex. Current tests for ToM are cognitive in nature, but it is clear from the literature that ToM is a module that developed for predicting behavior in a complex social situation, and thus has an emotional component (Povinelli \& Preuss, 1995; Stone et al., 1998). It is obvious that empathy, or the ability to experience another person's point of view, is critical for works in the arts but perhaps less so for works in the sciences. Using ToM abilities in creativity tests can expand our concept of what it means to be creative, especially to be creative in the arts or in a complex social situation. The framework makes overtly clear this link between the prefrontal cortex, ToM, and creativity.

Thus, in addition to providing a coherent account that systematizes current data in the field of creativity, the new framework suggests many new avenues of research that are currently not considered in neuroscience and/or creativity. Its adoption would be heuristically beneficial.

\section{CONCLUSIONS}

Supportive evidence from psychology and neuroscience was reviewed in order to outline a framework of creativity that integrates current understanding of the functional neuroanatomy of normative information pro- cessing with the findings of creativity research. Although the model is admittedly tentative at present, it is proposed on the strength of its heuristic value, and it is hoped that it will encourage researchers from diverse backgrounds to address testable hypotheses derived from it.

Concisely stated, creativity results from the factorial combination of four kinds of mechanisms. Neural computation that generates novelty can occur during two modes of thought (deliberate and spontaneous) and for two types of information (emotional and cognitive). Regardless of how novelty is generated initially, circuits in the prefrontal cortex perform the computation that transforms the novelty into creative behavior. To that end, prefrontal circuits are involved in making novelty fully conscious, evaluating its appropriateness, and ultimately implementing its creative expression.

From the proposed framework, a systematic reorganization of a substantial body of creativity research emerges that has a number of advantages over other theoretical approaches. First, the framework provides a coherent neuroscientific account of a wide variety of well-known phenomena, and thus places the hitherto dissociated area of creativity on a neural basis. Second, it unites into one framework a substantial amount of disparate research within the field of creativity that currently cannot be satisfactorily explained by any other single theory of creativity. The resulting novel synthesis clarifies a surprising number of classical controversies in creativity researchthat is, by distinguishing among several types of creativity, the framework permits the dissociation of factors such as knowledge, domain, and age, and systematizes the relationship of each of these influences to the creative process. Finally, the framework opens new lines of research that can greatly expand our knowledge base of this undervalued area of psychological science.

\section{REFERENCES}

Amabile, T. (1983). The social psychology of creativity. New York: Springer-Verlag.

Anderson, J. R., \& Bower, G. H. (1973). Human associative memory. Washington, DC: Winston.

Ashby, G. F., Isen, A. M., \& Turken, A. U. (1999). A neuropsychological theory of positive affect and its influence on cognition. Psychological Review, 106, 529-550.

Ashby, G. F., Valentin, V. V., \& Turken, A. U. (2002). The effects of positive affect and arousal on working memory and executive attention: Neurobiology and computational models. In S. Moore \& M. Oaksford (Eds.), Emotional cognition: From brain to behaviour (pp. 245-287). Amsterdam: Benjamins.

Axelrod, B. N., Jiron, C. C., \& Henry, R. R. (1993). Performance of adults ages 20 to 90 on the abbreviated Wisconsin Card Sorting Test. Clinical Neuropsychology, 7, 205-209.

BAARs, B. J. (1989). A cognitive theory of consciousness. Cambridge: Cambridge University Press.

BADDELEY, A. (1996). Exploring the central executive. Quarterly Journal of Experimental Psychology, 49A, 5-28.

BADDELEY, A. (2000). The episodic buffer: A new component of working memory. Trends in Cognitive Sciences, 4, 417-423.

Baker-SennetT, J., \& Ceci, S. (1996). Clue-efficiency and insight: Unveiling the mystery of inductive leaps. Journal of Creative Behavior, 30, 153-172.

Bekhtereva, N. P., Dan'ko, S. G., Starchenko, M. G., Pakhomov, 
S. V., \& Medvedev, S. V. (2001). Study of the brain organization of creativity: III. Positron-emission tomography data. Human Physiology, 27, 390-397.

Bekhtereva, N. P., Starchenko, M. G., Klyucharev, V. A., Vorob'ev, V. A., Pakhomov, S. V., \& Medvedev, S. V. (2000). Study of the brain organization of creativity: II. Positron-emission tomography data. Human Physiology, 26, 516-522.

Boden, J. E., \& Boden, G. M. (1969). The other side of the brain III: The corpus callosum and creativity. Bulletin of the Los Angeles Neurological Society, 34, 191-203.

Boden, M. A. (1998). Creativity and artificial intelligence. Artificial Intelligence, 103, 347-356.

Boone, B. K. (1999). Neuropsychological assessment of executive functions. In B. L. Miller \& J. L. Cummings (Eds.), The human frontal lobes: Functions and disorders (pp. 247-260). New York: Guilford.

Bransford, J. D., \& Stein, B. S. (1984). The ideal problem solver. New York: Freeman.

Braun, A. R., Balkin, T. J., Wesensten, N. J., Gwadry, F., Carson, R. E., Varga, M., Baldwin, P., Selbie, S., Belenky, G., \& Herscovitch, P. (1997). Regional cerebral blood flow throughout the sleep-wake cycle. Brain, 120, 1173-1197.

Broadbent, D. A. (1958). Perception and communication. New York: Pergamon.

BRUCKNER, R. L. (1996). Beyond HERA: Contributions of specific prefrontal brain areas to long-term memory retrieval. Psychonomic Bulletin \& Review, 3, 149-158.

CABEZA, R., \& NYBERG, L. (2000). Imaging cognition II: An empirical review of 275 PET and fMRI studies. Journal of Cognitive Neuroscience, 12, 1-47.

Cadoret, G., Pike, G. B., \& Petrides, M. (2001). Selective activation of the ventromedial prefrontal cortex in the human brain during active retrieval processing. European Journal of Neuroscience, 14, 11641170 .

Carlsson, I., Wendt, P. E., \& Risberg, J. (2000). On the neurobiology of creativity: Differences in frontal activity between high and low creative subjects. Neuropsychologia, 38, 873-885.

Channon, S., \& Crawford, S. (1999). Problem-solving in real-lifetype situations: The effect of anterior and posterior lesions on performance. Neuropsychologia, 37, 757-770.

Churchland, P. S. (2002). Brain-wise. Cambridge, MA: MIT Press.

Collins, A. M., \& LofTus, E. F. (1975). A spreading activation theory of semantic processing. Psychological Review, 82, 407-428.

Conway, A. A. R., Cowan, N., \& Bunting, M. F. (2001). The cocktail party phenomenon revisited: The importance of working memory capacity. Psychonomic Bulletin \& Review, 8, 331-335.

Courtney, S. M., Petit, L., Haxby, J. V., \& Ungerleider, L. G. (1998). The role of prefrontal cortex in working memory: Examining the contents of consciousness. Philosophical Transactions of the Royal Society of London: Series $B, \mathbf{3 5 3}, 1819-1828$.

Cowan, N. (1995). Attention and memory: An integrated framework. Oxford Psychology Series, No. 26. New York: Oxford University Press.

CowAN, N. (2001). The magical number 4 in short-term memory: A reconsideration of mental storage capacity. Behavioral \& Brain Sciences, 24, 87-185.

CRICK, F. H. C., \& КосH, C. (1998). Consciousness and neuroscience. Cerebral Cortex, 8, 97-107.

Csikszentminalyi, M. (1996). Society, culture, person: A systems view of creativity. In R. J. Sternberg (Ed.), The nature of creativity (pp. 325-339). Cambridge: Cambridge University Press.

Damasio, A. R. (1994). Descartes' error: Emotion, reason, and the human brain. New York: Putnam.

Damasio, A. R. (2001). Some notes on brain, imagination and creativity. In K. H. Pfenninger \& V. R. Shubik (Eds.), The origins of creativity (pp. 59-68). Oxford: Oxford University Press.

Damasio, A. R. (2002). Conference proceedings: Neuroethics. Mapping the field. New York: Dana.

DeBono, E. (1968). New think: The use of lateral thinking in the generation of new ideas. New York: Basic Books.

Dehaene, S., \& Naccache, L. (2001). Toward a cognitive science of consciousness: Basic evidence and a workspace framework. Cognition, 79, 1-37.
Desgranges, B., Baron, J.-C., \& Eustache, F. (1997). The functional neuroanatomy of episodic memory: The role of the frontal lobes, the hippocampal formation, and other areas. NeuroImage, $\mathbf{8}, 198-213$.

DiETRICH, A. (2003). Functional neuroanatomy of altered states of consciousness. The transient hypofrontality hypothesis. Consciousness \& Cognition, 12, 231-256.

DiETRICH, A. (2004). Neurocognitive mechanisms underlying the experience of flow. Consciousness \& Cognition, 13, 746-761.

Dietrich, A., \& ALLEn, J. D. (1998). Functional dissociation of the prefrontal cortex and the hippocampus in timing behavior. Behavioral Neuroscience, 112, 1043-1047.

Dietrich, A., TAYlor, J. T., \& PASSMORe, C. E. (2001). AVP (4-8) improves concept learning in PFC-damaged but not hippocampaldamaged rats. Brain Research, 919, 41-47.

Duncan, J., \& OWEN, A. M. (2000). Common regions of the human frontal lobe recruited by diverse cognitive demands. Trends in Neurosciences, 23, 475-483.

DUNCKER, K. (1945). On problem solving. Psychological Monographs, 585, (No 270).

EYSENCK, H. J. (1993). Creativity and personality: Suggestions for a theory. Psychological Inquiry, 4, 147-178.

EySENCK, H. J. (1995). Genius: The natural history of creativity. Cambridge: Cambridge University Press.

Fink, G. R., Markowitsch, H. J., Reinkemeier, M., Bruckbauer, T., Kessler, J., \& HeIss, W. D. (1996). Cerebral representation of one's own past: Neural networks involved in autobiographical memory. Journal of Neuroscience, 16, 4275-4282.

FINKE, R. A. (1996). Imagery, creativity, and emergent structure. Consciousness \& Cognition, 5, 381-393.

Fletcher, P. C., Anderson, J. M., Shanks, D. R., Honey, R., CarPenter, T. A., Donovan, T., Papdakis, N., \& Bullmore, E. T. (2001). Responses of the human frontal cortex to surprising events are predicted by formal associative learning theory. Nature Neuroscience, 4, 1043-1048.

FrênSCH, P. A., \& Sternberg, R. J. (1989). Expertise and intelligent thinking: When is it worse to know better? In R. J. Sternberg (Ed.), $A d$ vances in the psychology of human intelligence (Vol. 5, pp. 157-188). Hillsdale, NJ: Erlbaum.

Friedman, R. S., \& Förster, J. (2002). The influence of approach and avoidance motor actions on creative cognition. Journal of Experimental Social Psychology, 38, 41-55.

FRITH, C. D., \& Dolan, R. (1996). The role of the prefrontal cortex in higher cognitive functions. Cognitive Brain Research, 5, 175-181.

Frith, C. D., \& Frith, U. (2001). Cognitive psychology-Interacting minds-A biological basis. Science, 286, 1692-1695.

Fuster, J. M. (1995). Temporal processing-Structure and function of the human prefrontal cortex. Annals of the New York Academy of Sciences, 769, 173-181.

FUSTER, J. M. (2000a). Executive frontal functions. Experimental Brain Research, 133, 66-70.

FuSTER, J. M. (2000b). The prefrontal cortex of the primate: A synopsis. Psychobiology, 28, 125-131.

FusteR, J. M. (2002). Frontal lobe and cognitive development. Journal of Neurocytology, 31, 373-385.

GABRIELI, J. D. E. (1998). Cognitive neuroscience of human memory. Annual Review of Psychology, 49, 87-115.

GARDNER, H. (1993). Creating minds: An anatomy of creativity seen though the lives of Freud, Einstein, Picasso, Stravinsky, Eliot, Graham, and Gandhi. New York: Basic Books.

Gazzaniga, S. M., Ivry, R. B., \& Mangun, G. R. (1998). Cognitive neuroscience. New York: Norton.

Gilbert, P. F. C. (2001). An outline of brain function. Cognitive Brain Research, 12, 61-74.

GoLDMAN-RAKIC, P. S. (1992). Working memory and the mind. Scientific American, 267, 111-117.

GoodwIN, D. W. (1992). Alcohol as muse. American Journal of Psychotherapy, 46, 422-433.

Gruber, H. E. (1981). Darwin on man: A psychological study of scientific creativity. Chicago: University of Chicago Press.

GuILFORD, J. P. (1950). Creativity. American Psychologist, 5, 444-454.

GuILFord, J. P. (1967). The nature of human intelligence. New York: McGraw-Hill. 
GUILFORD, J. P. (1982). Is some creative thinking irrational? Journal of Creative Behavior, 16, 151-154.

Halford, G. S., Wilson, W. H., \& Phillips, S. (1998). Processing capacity defined by relational complexity: Implications for comparative, developmental, and cognitive psychology. Behavioral \& Brain Sciences, 21, 723-802.

HARTMAN, E. (1966). The psychophysiology of free will. In R. Lowenstein, L. Newman, \& A. Solnit (Eds.), Psychoanalysis: A general psychology. New York: International University Press.

Hasegawa, I., Hayashi, T., \& Miyashita, Y. (1999). Memory retrieval under the control of the prefrontal cortex. Annals of Medicine, 31, 380-387.

HAYES, R. R. (1989). Cognitive processes in creativity. In J. A. Glover, R. R. Ronning, \& C. R. Reynolds (Eds.), Handbook of creativity (pp. 135-145). New York: Plenum.

HeBb, D. O. (1939). Intelligence in man after large removal of cerebral tissue: Report of four left frontal lobe cases. Journal of General Psychology, 21, 73-87.

Hobson, J. A. (1988). The dreaming brain. New York: Basic Books.

Hobson, J. A., \& McCARLEY, R. (1977). The brain as a dream-state generator: An activation-synthesis hypothesis of the dream process. American Journal of Psychiatry, 134, 1335-1348.

Hobson, J. A., Pace-Schott, E. F., \& Stickhold, R. (2000). Dreaming and the brain: Toward a cognitive neuroscience of conscious states. Behavioural \& Brain Sciences, 23, 793-842.

Hull, D. L., Tessner, P. D., \& Diamond, A. M. (1978). Planck's principle: Do younger scientists accept new scientific ideas with greater alacrity than older scientists? Science, 202, 717-723.

JAMISON, K. R. (1993). Touched by fire: Manic depressive illness and the artistic temperament. New York: Free Press.

JANOWSKy, J. S., Shimamura, A. P., \& SQuire, L. R. (1989). Source memory impairment in patients with frontal lobe lesions. Neuropsychologia, 27, 1043-1056.

JASPER, H. H. (1995). A historical perspective: The rise and fall of prefrontal lobotomy. Advances in Neurology, 66, 97-114.

Kane, M. J., Bleckley, M. K., Conway, A. R. A., \& Engle, R. W. (2001). A controlled-attention view of working-memory capacity. Journal of Experimental Psychology: General, 130, 169-183.

KATZ, A. N. (1986). The relationship between creativity and cerebral hemisphericity for creative architects, scientists, and mathematicians. Empirical Studies of the Arts, 4, 97-108.

Keenan, J. P., Wheeler, M. A., Gallup, G. G., \& Pascual-Leone, A. (2000). Self-recognition and the right prefrontal cortex. Trends in Cognitive Sciences, 4, 338-344.

KESNER, R. P., \& HOLBROOK, T. (1987). Dissociation of item and order spatial memory in rats following medial prefrontal cortex lesions. Neuropsychologia, 25, 653-664.

KIKYO, H., OHKI, K., \& SEKIHARA, K. (2001). Temporal characterization of memory retrieval processes: An fMRI study of the "tip of the tongue" phenomenon. European Journal of Neuroscience, 14, 887-892.

Kinsbourne, M. (1982). Hemispheric specialization and the growth of human understanding. American Psychologist, 37, 411-420.

Knight, R. T., \& Grabowecky, M. (1999). Prefrontal cortex, time, and consciousness. In M. S. Gazzaniga (Ed.), The cognitive neurosciences (2nd ed., pp. 1319-1337). Cambridge, MA: MIT Press.

Knoblich, G., Ohlsson, S., Haider, H., \& Rhenius, D. (1999). Constraint relaxation and chunk decomposition in insight problem solving. Journal of Experimental Psychology: Learning, Memory, \& Cognition, 25, 1534-1555.

Koechlin, E., Basso, G., Pietrini, P., Panzer, S., \& Grafman, J. (1999). The role of the anterior prefrontal cortex in human cognition. Nature, 399, 148-151.

KOESTLER, A. (1964). The act of creation. New York: Macmillan.

Kolb, B. (1984). Functions of the prefrontal cortex in the rat: A comparative view. Brain Research Review, 8, 65-98.

Kolb, B., \& WhishaW, I. Q. (1983). Problems and principles in crossspecies generalizations. In E. T. Robinson (Ed.), Behavioral contribution to brain research (pp. 266-287). Oxford: Oxford University Press.

Konishi, S., NaKajima, K., Uchida, I., Kameyama, M., NaKahara, K., Sekihara, K., \& Miyashita, Y. (1998). Transient activa- tion of the inferior prefrontal cortex during cognitive set shifting. $\mathrm{Na}$ ture Neuroscience, 1, 80-84.

KorNHUBER, H. H. (1993). Prefrontal cortex and homo-sapiens-on creativity and reasoned will. Neurological Psychiatry \& Brain Research, 2, 1-6.

Kunn, T. (1970). The structure of scientific revolutions (2nd ed.). Chicago: University of Chicago Press.

LeDoux, J. (1996). The emotional brain. New York: Touchstone.

Lehman, H. C. (1953). Age and achievement. Princeton, NJ: Princeton University Press.

LHERMitTE, F. (1983). "Utilization behaviour" and its relation to lesions of the frontal lobes. Brain, 106, 237-255.

Lhermitte, F., Pillon, B., \& SERDARU, M. (1986). Human autonomy and the frontal lobes: Part I. Imitation and utilization behavior: A neuropsychological study of 75 patients. Annals of Neurology, 19, 326-334.

Lunchins, A. S., \& Lunchins, E. H. (1959). Rigidity of behavior. Eugene: University of Oregon Press.

Markowitsch, H. J. (1995). Cerebral bases of consciousness: A historical view. Neuropsychologia, 33, 1181-1192.

Martindale, C. (1995). Creativity and connectionism. In S. M. Smith, T. B. Ward, \& R. A. Finke (Eds.), The creative cognition approach (pp. 249-268). Cambridge, MA: MIT Press.

Martindale, C. (1999). The biological basis of creativity. In R. J. Sternberg (Ed.), Handbook of creativity (pp. 137-152). Cambridge: Cambridge University Press.

Mayberg, H. S. (1997). Limbic-cortical dysregulation: A proposed model of depression. Journal of Neuropsychiatry \& Clinical Neuroscience, 9, 471-481.

MEANS, L. W., \& Holstein, R. D. (1992). Individual aged rats are impaired on repeated reversals due to loss of different behavioral patterns. Physiology \& Behavior, 52, 959-963.

MednicK, S. A. (1962). The associative basis of the creative process. Psychological Review, 69, 220-232.

MEtCALFe, J. (1986). Feelings of knowing in memory and problem solving. Journal of Experimental Psychology: Learning, Memory, \& Cognition, 12, 288-294.

Miller, B. L., Cummings, J., Mishin, F., Boone, K., Prince, F., PonTON, M., \& Cotman, C. (1998). Emergence of artistic talent in frontotemporal dementia. Neurology, 51, 978-982.

Miller, E. K., \& CoheN, J. D. (2001). An integrative theory of prefrontal cortex function. Annual Review of Neuroscience, 24, 167-202.

Milner, B. (1995). Aspects of human frontal lobe function. Advances in Neurology, 66, 67-84.

Mishkin, M., Malamut, B., \& Bachevalier, J. (1984). Memory and habit: Two neural systems. In G. Lynch, J. J. McGaugh, \& N. M. Weinberger (Eds.), Neurobiology of learning and memory (pp. 6677). New York: Guilford.

Monchi, O., Petrides, M., Petre, V., Worsley, K., \& Dagher, A. (2001). Wisconsin card sorting revisited: Distinct neural circuits participating in different stages of the task identified by event-related functional magnetic resonance imaging. Journal of Neuroscience, $\mathbf{2 1}$, 7733-7741.

NisBETT, R. E., \& Ross, L. (1980). Human inference: Strategies and shortcomings of social judgments. Englewood Cliffs, NJ: PrenticeHall.

Norman, D. A., \& Shallice, T. (1986). Attention to action: Willed and automatic control of behavior. In R. S. Davidson, G. E. Schwartz, \& D. Shapiro (Eds.), Consciousness and self-regulation (pp. 1-18). New York: Plenum.

NyBERG, L. (1998). Mapping episodic memory. Behavioural Brain Research, 90, 107-114.

PETRIDES, M. (1996). Specialized systems for the processing of mnemonic information within the primate frontal cortex. Philosophical Transactions of the Royal Society of London: Series B, 351, 1455-1462.

PeTRIDES, M., \& PANDYA, D. N. (1999). Dorsolateral prefrontal cortex: Comparative cytoarchitectonic analysis in the human and the macaque brain. European Journal of Neuroscience, 11, 1011-1036.

Pfenninger, K. H., \& ShubiK, V. R. (2001). Insights into the foundation of creativity: A synthesis. In K. H. Pfenninger \& V. R. Shubik (Eds.), The origins of creativity (pp. 213-236). Oxford: Oxford University Press. 
PINKER, S. (1999). How the mind works. New York: Norton.

Posner, M. (1994). Attention: The mechanism of consciousness. Proceedings of the National Academy of Sciences, 91, 7398-7403.

Post, F. (1994). Creativity and psychopathology: Astudy of 291 worldfamous men. British Journal of Psychiatry, 165, 22-34.

Post, F. (1996). Verbal creativity, depression and alcoholism: An investigation of one hundred American and British writers. British Journal of Psychiatry, 168, 545-555.

Povinelli, D. J., \& Preuss, T. M. (1995). Theory of mind: Evolutionary history of a cognitive specialization. Trends in Neurosciences, $\mathbf{1 8}$, 418-424.

Quintana, J., \& Fuster, J. M. (1999). From perception to action: Temporal integrative function of prefrontal and parietal neurons. Cerebral Cortex, 9, 213-221.

Rechtschaffen, A. (1978). The single-mindedness and isolation of dreams. Sleep, 1, 97-109.

Rothenberg, A. (2001). Bipolar illness, creativity, and treatment. Psychiatry Quarterly, 72, 131-147.

RYLANDER, G. (1948). Personality analysis before and after frontal lobotomy. Research Publication-Association for Research in Nervous \& Mental Disease, 27, 691-705.

Sarter, M., Givens, B., \& Bruno, J. P. (2001). The cognitive neuroscience of sustained attention: Where top-down meets bottom-up. Brain Research Reviews, 35, 146-160.

SASS, L. A. (2000). Schizophrenia, modernism, and the "creative imagination": On creativity and psychopathology. Creativity Research Journal, 13, 55-74.

ScHEIBEL, A. B. (1999). Creativity and the brain. Available at http://www. pbs.org/teachersource/scienceline/archives/sept99/sept99.shtm.

Schooler, J. W., \& Melcher, J. (1995). The ineffability of insight. In S. M. Smith, T. B. Ward, \& R. A. Finke (Eds.), The creative cognition approach (pp. 97-133). Cambridge, MA: MIT Press.

Shallice, T., \& Burgess, W. (1991). Deficits in strategy application following frontal lobe damage in man. Brain, 114, 727-741.

Shirley, D. A., \& Langan-Fox, J. (1996). Intuition: A review of the literature. Psychological Reports, 79, 563-584.

Simonton, D. K. (1975). Creativity, task complexity, and intuitive versus analytical problem solving. Psychological Reports, 37, 351-354.

Simonton, D. K. (1988). Creativity, leadership, and chance. In R. J. Sternberg \& J. E. Davidson (Eds.), The nature of creativity: Current psychological perspectives (pp. 386-426). Cambridge, MA: MIT Press.

Simonton, D. K. (1997). Creative productivity: A predictive and explanatory model of career trajectories and landmarks. Psychological Review, 104, 66-89.

SIMONTON, D. K. (1999). Creativity from a historiometric perspective. In R. J. Sternberg (Ed.), Handbook of Creativity (pp. 116-133). Cambridge: Cambridge University Press.

Simonton, D. K. (2000). Creativity: Cognitive, personal, developmental, and social aspects. American Psychologist, 55, 151-158.

Simonton, D. K. (2003). Scientific creativity as constrained stochastic behavior: The integration of product, person, and process. Psychological Bulletin, 129, 475-494.

SINGER, J. L. (1975). Navigating the stream of consciousness: Research in daydreaming and related inner experiences. American Psychologist, 30, 727-738.

SINGER, J. L. (1978). Experimental studies of daydreaming and the stream of thought. In K. S. Pope \& J. L. Singer (Eds.), The stream of consciousness: Scientific investigations into the flow of human experience (pp. 209-227). New York: Plenum.

SQuire, L. R. (1992). Memory and the hippocampus: A synthesis from findings with rats, monkeys and humans. Psychological Review, $\mathbf{9 9}_{2}$ 195-231.

SternberG, R. J., \& Lubart, T. I. (1995). An investment perspective on creative insight. In R. J. Sternberg \& J. E. Davidson (Eds.), The nature of insight (pp. 386-426). Cambridge, MA: MIT Press.

SternberG, R. J., \& Lubart, T. I. (1999). The concept of creativity: Prospects and paradigms. In R. J. Sternberg (Ed.), Handbook of creativity (pp. 3-15). Cambridge: Cambridge University Press.

Stone, V. E., Baron-Cohen, S., \& Knight, R. T. (1998). Frontal lobe contributions to the theory of mind. Journal of Cognitive Neuroscience, 10, 640-656.

TAYLOR, J. G. (2001). The central role of the parietal lobes in consciousness. Consciousness \& Cognition, 10, 379-417.

TAYLOR, S. F. (1996). Cerebral blood flow and functional lesions in schizophrenia. Schizophrenia Research, 19, 129-140.

Torrance, E. P. (1974). Torrance test of creative thinking. Lexington, MA: Personal Press.

Torrance, E. P. (1988). Intense emotional experiences-impetus for creation. Creative Child \& Adult Quarterly, 11, 130-137.

Torrance, E. P., \& Hall, L. K. (1980). Assessing the further reaches of creative potential. Journal of Creative Behavior, 14, 1-19.

Vogeley, K., Bussfeld, P., Newen, A., Herrman, S., Happe, F., Falkai, P., Maier, W., Shah, N. J., Fink, G. R., \& Zilles, K. (2001). Mind reading: Neural mechanisms of theory of mind and selfperspective. NeuroImage, 14, 170-181.

Vogeley, K., Kurthen, M., FALKaI, P., \& Maier, W. (1999). Essential functions of the human self model are implemented in the prefrontal cortex. Consciousness \& Cognition, 8, 343-363.

WAdDEll, C. (1998). Creativity and mental illness: Is there a link? Canadian Journal of Psychiatry, 43, 166-172.

WARD, T. B., SMITH, S. M., \& FInke, R. A. (1999). Creative cognition. In R. J. Sternberg (Ed.), Handbook of creativity (pp. 189-212). Cambridge: Cambridge University Press.

WeIsberg, R. W. (1993). Creativity: Beyond the myth of genius. New York: Freeman.

WeISBERG, R. W. (1999). Creativity and knowledge: A challenge to theories. In R. J. Sternberg (Ed.), Handbook of creativity (pp. 226-250). Cambridge: Cambridge University Press.

Weisberg, R. W., \& Alba, J. W. (1981). An examination of the alleged role of "fixation" in the solution of several "insight" problems. Journal of Experimental Psychology: General, 110, 169-192.

WertheIMER, M. (1982). Productive thinking. Chicago: University of Chicago Press.

(Manuscript received June 26, 2003; revision accepted for publication December 18, 2003.) 